\title{
Variabilidade morfológica da praia do Pântano do Sul, ilha de Santa Catarina, Brasil
}

\author{
Ulisses Rocha de Oliveira ${ }^{1}$, Rodrigo do Carmo Barletta ${ }^{2}$, Janice Rezende Vieira Peixoto ${ }^{3} \&$ \\ Norberto Olmiro Horn Filho ${ }^{4}$
}

\begin{abstract}
Resumo Este trabalho visa analisar a variabilidade morfológica de perfis de praia obtidos na praia do Pântano do Sul, sul da ilha de Santa Catarina. Três perfis de praia foram analisados, mensalmente, entre agosto de 2002 e agosto de 2003. Um perfil extra foi realizado para elucidar a presença de megacúspides. Características de onda na zona de surf foram medidas através da observação visual a cada perfil. Durante o período de amostragem dos perfis de praia, o regime de ondas em águas profundas também foi monitorado, através de dados coletados por um ondógrafo direcional localizado a cerca de $35 \mathrm{~km}$ da ilha de Santa Catarina. As variações morfológicas dos perfis ocorreram em decorrência de quatro principais fatores: (i) Do grau de exposição dos diferentes trechos da praia às ondas incidentes. Quando mais exposta à ação de ondas, a praia tendeu a apresentar maiores variações no estoque sedimentar; (ii) Da ação de ondas de alta energia na praia, caracterizada pela incidência de ondulações de sul-sudeste com período de pico de onda acima de $10 \mathrm{~s}$ e altura significativa acima de 4 m, em águas profundas, condição que gera erosão da porção subaérea da praia; (iii) Da ação de ondas de baixa energia na praia, que geralmente acarreta deposição sedimentar da praia subaérea; (iv) Da própria morfologia rítmica da praia, que pode gerar variações locais na declividade e no volume entre perfis medidos sobre pontas ou embaiamentos das megacúspides.
\end{abstract}

Palavras-chave: perfis de praia, morfodinâmica praial, praia de enseada.

\begin{abstract}
Morphologic variability to beach profiles measures in Pântano do Sul beach, Santa Catarina island, Brazil. This work aims at analyzing some beach morphologic variability profiles which have been measured on Pântano do Sul beach, south of Santa Catarina Island. Three beach profiles have been monitored along the beach from August 2002 to August 2003 in a monthly rate. An extra profile has been measured in order to clarify the presence of megacusps. Wave characteristics in the surf zone have been monitored through visual observation in each profile. The wave regime in deep waters has also been assessed during the beach profile sampling period by using data collected by a directional wave rider buoy placed approximately $35 \mathrm{~km}$ from the Santa Catarina Island. The profiles morphological variations have taken place due to four main reasons: (i) the wave average energy variability among the three sectors thus reflecting the exposure level of the various parts of the beach to the incident waves. The more the beach is exposed to the waves action, the more are the variations in its sedimentary stock; (ii) high wave energy, characterized by South-Southeast swells with peak periods above 10 seconds and significant wave height above $4 \mathrm{~m}$ in deep waters, condition which erodes the subaereal portion of the beach; (iii) persistent low wave energy, which usually brings on sediment to the beach; (iv) the rhythmic beach morphology itself, which may trigger local variations in the beach face slope as well as in its volume among profiles measured on megacusps crests or on megacusps embayments.
\end{abstract}

Keywords: beach profiles, beach morphodynamics, embayed beach.

INTRODUÇÃo As praias arenosas são alguns dos ambientes mais dinâmicos e sensíveis da Terra. A extensão e características morfodinâmicas das praias arenosas dependem basicamente da variação da maré, do regime de onda, do tamanho do grão e da forma da praia em planta (Short 1999).

Em zonas costeiras onde há presença do em- basamento cristalino, como em boa parte do litoral de Santa Catarina, praias arenosas de enseada, com diferentes orientações, formas e dinâmica são comuns. Em relação ao grau de exposição às ondas, as praias arenosas desta região podem ser protegidas, semiprotegidas e expostas a energia das ondas. Geralmente, quanto maior for a exposição de uma praia à ação de ondas, maiores

1 - Programa de Pós Graduação em Geografia, CFH, Universidade Federal de Santa Catarina, Florianópolis (SC), Brasil.

E-mail: ulisseslicke@yahoo.com.br

2 - Programa de Pós-graduação em Engenharia Ambiental, Laboratório de Hidráulica Marinha, CTC, Universidade Federal de Santa

Catarina, Florianópolis (SC), Brasil. E-mail: rodrigobarletta@hotmail.com

3 - Programa de Pós-graduação em Geografia, CFH, Universidade Federal de Santa Catarina, Florianópolis (SC), Brasil.

E-mail: tartbr@yahoo.com.br

4 - Departamento de Geociências, CFH, Universidade Federal de Santa Catarina, Florianópolis (SC), Brasil. E-mail: horn@cfh.ufsc.br 
tenderão a serem as variações morfológicas decorrentes (Klein et al. 1997).

Variações na morfologia das praias arenosas, com movimentação transversal de sedimentos, relacionam-se a ciclos de erosão e deposição de sedimentos, com erosão do perfil subaéreo geralmente como resposta a condições de maior energia de onda, vento e/ou maré, dependendo da ação de cada agente específico, e deposição de sedimentos na porção subaérea em condições de menor energia desses agentes na costa (Sunamura 1988). Alterações na morfologia das praias também ocorrem como resposta à deriva litorânea, gerando transporte sedimentar ao longo das praias e mesmo entre praias vizinhas.

Dentro deste contexto, este trabalho visa analisar a variabilidade morfológica da praia do Pântano do Sul, uma praia de enseada localizada no litoral do Estado de Santa Catarina, Sul do Brasil, de modo a relacionar a variabilidade de perfis medidos à própria geomorfologia da costa, ao grau de exposição de diferentes trechos da praia, a ação do regime de ondas no período de monitoramento e a feições rítmicas de menor amplitude morfológica encontradas durante a medição dos perfis.

ÁREA DE ESTUDO A praia do Pântano do Sul é uma praia de enseada localizada no sul da ilha de Santa Catarina (Fig. 1). Mede $3.920 \mathrm{~m}$ de comprimento estando delimitada pelos promontórios rochosos da ponta do Marisco, a nordeste, e da ponta da Régua, a sudoeste. Apresenta linha de costa mais curvada em planta na porção nordeste, próximo à localidade de Pântano do Sul, onde a orientação predominante é leste-oeste. Em direção a sudoeste, a partir do Balneário dos Açores, a orientação predominante da linha de costa é nordestesudoeste. Neste trecho, a praia tem uma linha de costa mais retilínea em planta. Esta praia possui areias finas a muito finas, bem a muito bem selecionadas em toda sua extensão, com diâmetro médio um pouco menor próximo à localidade do Pântano do Sul, setor nordeste da praia (Oliveira 2004).

A área de estudo está submetida ao regime de micromarés, com amplitude máxima de 1,4 $\mathrm{m}$, semidiurno. No litoral catarinense, as maiores variações de nível de maré ocorrem devido à forçantes meteorológicas (Mariotti \& Franco 2001).

As características meteorológicas da região são controladas pela atuação das massas Polar Marítima e Tropical Marítima do Atlântico, estando sob clima temperado de categoria subquente (Nimer 1989). A circulação atmosférica da região é caracterizada pelo domínio de um sistema semifixo de alta pressão gerando ventos de nortenordeste, juntamente com o efeito local da brisa marinha. Periodicamente, o sistema é perturbado pela passagem de frentes frias originadas pela migração do Anticiclone Polar Móvel sobre a região. Estas frentes frias comumente geram ciclones extratropicais em sua porção oceânica, migrando de sudoeste para nordeste (Mariotti \& Franco 2001). Os fortes ventos originados pelos ciclones normalmente geram grande agitação marítima e sobreelevação do nível marinho junto à costa (Trucollo 1998).

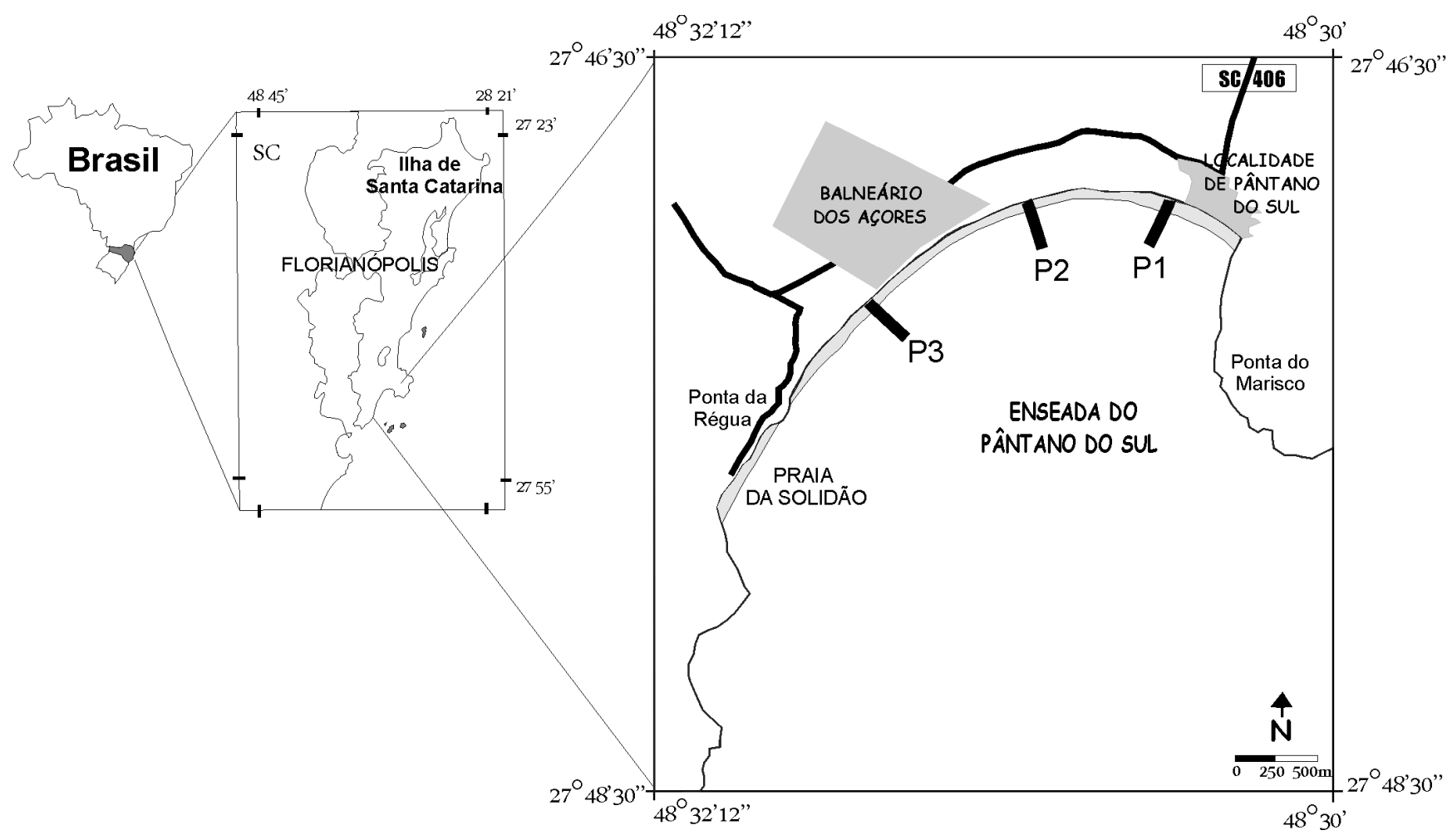

Figura 1 - Mapa da área de estudo, situada a leste da ilha de Santa Catarina, e dos perfis de praia analisados (P1, P2 e P3). 
Segundo um estudo sobre o regime de ondas ao largo da ilha de Santa Catarina, realizado por Araújo et al. (2003), predominam ao longo do ano ondulações (swells) provindas do quadrante sul, com período de pico de onda em torno de $12 \mathrm{~s}$, e vagas (sea waves) do quadrante leste, com período de pico de onda de $8 \mathrm{~s}$. Durante o outono e inverno, as ondulações de sul prevalecem sobre as vagas de leste; no verão há um balanço entre elas e na primavera prevalecem as vagas de leste. Segundo estes autores, condições de alta energia de onda geralmente associam-se à atuação de ondulações de sul-sudeste, com períodos de pico de onda acima de $10 \mathrm{~s}$ e ondas maiores que $4 \mathrm{~m}$ em águas profundas, podendo ser encontradas em todas as estações do ano.

MATERIAIS E MÉTODOS Para realização do monitoramento praial, três marcos topográficos artificiais foram fixados sobre a planície costeira em três pontos da costa, onde foram monitorados os perfis de praia (Fig. 1). O perfil 1 localiza-se no setor nordeste da praia do Pântano do Sul, o perfil 2 localiza-se no setor central da praia e o perfil 3 localiza-se no setor sudoeste. A localização dos perfis foi escolhida após a análise de fotografias aéreas da área de estudo e trabalhos de campo preliminares. A escolha destes locais foi baseada principalmente no tocante às diferenças entre si tanto quanto às feições geomorfológicas da planície costeira como quanto à orientação da linha de costa. Pertencem desse modo a três setores distintos ao longo da praia. Durante a realização dos perfis de praia, foram efetuadas coletas superficiais de sedimentos na face praial e observações visuais de características de onda.

Os perfis foram medidos mensalmente, entre agosto de 2002 e agosto de 2003 (13 campanhas), utilizando o método de nivelamento expedito com nível e estádia descrito em Birkmeier (1981). Um perfil extra foi medido no dia 13/06/2003, localizado a $78 \mathrm{~m}$ a norte-nordeste do perfil 2, chamado de perfil $2 b$. Este perfil serviu para elucidar a presença de pontas e embaiamentos de megacúspides.

Um nível de referência arbitrário (datum) foi definido para cada perfil, possibilitando distinguir a porção subaérea e subaquosa do perfil. Estes valores aproximados em relação ao nível zero do mar foram obtidos em períodos de maré de sizígia baixa durante a amostragem dos dados. A data da maré de sizígia mais baixa coincidente com a amostragem dos dados foi determinada através da observação das tábuas de maré (DHN 2002, DHN 2003).

O processamento dos perfis foi realizado no programa computacional ISRP (Interactive Survey Reduction Program), implementado por Birkmeier (1985). Através do ISRP, foram obtidas as variações de volume subaéreo dos perfis, o que possibilitou o cálculo de células de erosão ou deposição relativas de volume entre perfis consecutivos. Também foram calculadas variações relativas acumuladas de volume para os três perfis medidos mensalmente, a partir da medição de agosto de 2002. O perfil extra (2b) foi "amarrado" ao mesmo marco topográfico e datum do perfil 2, o que possibili- tou o cálculo da variação de volume entre eles.

Características de onda na zona de surf, como altura significativa (diferença de nível entre a crista e o cavado de uma onda) e período de pico de onda (tempo medido em segundos da passagem de duas cristas de onda sobre um mesmo ponto), foram monitoradas através de observações visuais a cada perfil medido segundo a metodologia proposta por Melo (2002).

A caracterização do regime de ondas durante o monitoramento praial foi compilada a partir do trabalho de Araújo et al. (2003). Neste trabalho foram tratados estatisticamente dados de altura significativa, período e direção de onda, coletados por um ondógrafo direcional localizado a cerca de $35 \mathrm{~km}$ da ilha de Santa Catarina (leste da área de estudo) (Fig. 1) disponibilizados no site www.lahimar.ufsc.br e em Melo et al. (2003). O ondógrafo situa-se à distância da costa correspondente à profundidade de cerca de $80 \mathrm{~m}$. Para aferir a observação visual realizada na área de estudo, foram comparados os dados de onda (altura significativa, período e direção) do ondógrafo durante os dias de monitoramento praial.

Deve-se ressaltar que os dados coletados pelo ondógrafo referem-se a águas profundas e os dados de onda coletados na área de estudo foram coletados nas zonas de arrebentação e surf, a águas rasas. Os dados de onda em águas profundas foram utilizados para inferir a energia de onda de swell durante o monitoramento praial, enquanto que os coletados em águas rasas, medidos na zona de surf, serviram principalmente para medir a diferença de energia de quebra de onda, espacialmente ao longo da praia.

\section{RESULTADOS}

Variabilidade entre os perfis e ao longo do monitoramento $\mathrm{O}$ setor nordeste da praia (perfil 1), cuja orientação da costa é sudeste-noroeste, é abrigado da alta energia de onda. Este setor apresenta, na planície costeira, cordões litorâneos holocênicos e pequenas dunas frontais, havendo desenvolvimento de dunas frontais incipientes em períodos de deposição sedimentar e escarpas na duna frontal após períodos erosivos. Este trecho do arco praial é o que apresenta maior densidade urbana, estruturada em grande parte sobre as dunas frontais. A variação morfológica do perfil 1 ocorreu principalmente no pós-praia e face praial (berma) e secundariamente nas dunas frontais estabelecidas e frontais incipientes (Fig. 2).

No setor central da praia (perfil 2), situado num trecho de costa com orientação nordeste-sudoeste, semi-exposto a alta energia das ondas, ocorrem na planície costeira dunas transgressivas, estruturadas sobre cordões litorâneos holocênicos. As dunas frontais apresentaram-se escarpadas pela ação marinha durante o período de monitoramento (agosto de 2002 a agosto de 2003), não ocorrendo neste período de tempo o desenvolvimento de dunas frontais incipientes. O perfil 2 caracterizou um trecho com maior mobilidade sedimentar que o perfil 1 , ocorrendo desde a base da duna frontal até a porção subaquosa da praia (Fig. 2).

$\mathrm{O}$ setor sudoeste da praia (perfil 3), próximo 
Perfil 1
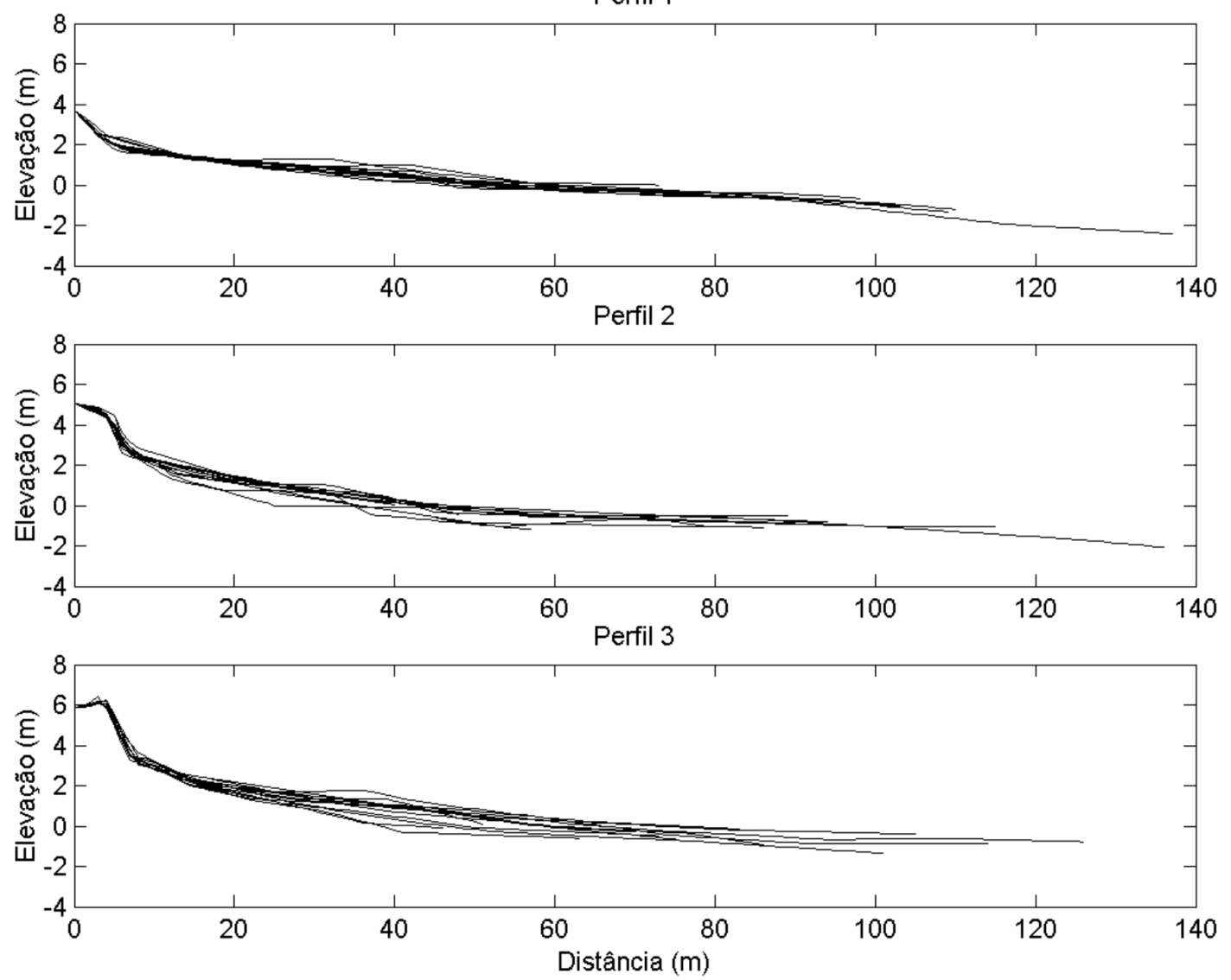

Figura 2 - Superfícies dos três perfis monitorados na praia do Pântano do Sul.

ao balneário de Açores, corresponde àquele onde a linha de costa passa a ser mais retilínea em planta, com orientação nordeste-sudoeste. Neste setor, cordões litorâneos holocênicos situados na planície costeira estão sendo retrabalhados pela ação marinha. Diferentemente dos outros setores, cordões litorâneos de idade pleistocênica encontram-se preservados na retaguarda dos cordões holocênicos. Neste trecho mais exposto, a escarpa frontal apresentou maior altura que no setor central (perfil 2). Nos períodos de deposição, ocorreu desenvolvimento de dunas frontais incipientes. O perfil 3 foi o que apresentou maior mobilidade no estoque sedimentar subaéreo da praia, principalmente próximo à face da praia (Fig. 2).

Quanto à variação ocorrida em cada perfil ao longo do tempo monitorado, o perfil 1 apresentou variações negativas de volume, erosivas, de setembro a novembro de 2002 e de março a junho de 2003 . Variações positivas ou deposicionais foram medidas de dezembro de 2002 a fevereiro de 2003 e também de julho a agosto de 2003 (Fig. 3). A maior taxa de deposição no volume subaéreo entre duas medições consecutivas ocorreu entre janeiro e fevereiro de $2003\left(+8,01 \mathrm{~m}^{3} / \mathrm{m}\right)$, enquanto que a maior taxa de erosão ocorreu entre março e abril de $2003\left(-8,79 \mathrm{~m}^{3} / \mathrm{m}\right)$. Os dados de variação de volume acumulado a partir da primeira campanha mostram que a porção subaérea da praia perdeu sedimentos até no- vembro de 2002, quando voltou a acumular sedimento. Seu máximo acrescivo foi observado na medição realizada em fevereiro de 2003, quando a praia também apresentou maior declividade na face praial, devido ao desenvolvimento de uma berma. A partir de abril, a praia começou a perder sedimentos novamente, chegando a seu maior déficit sedimentar medido no mês de julho de 2003. Ao final de 13 campanhas, o perfil 1 apresentou perda acumulada de $5,17 \mathrm{~m}^{3} / \mathrm{m}$ no estoque sedimentar subaéreo em relação ao primeiro perfil medido.

Já no perfil 2, situado na porção central, trecho com maior variação morfológica que no nordeste da praia (perfil 1), predominou a deposição de sedimentos entre agosto de 2002 e agosto de 2003. Perfis erosivos ocorreram apenas nos meses de setembro de 2002 e abril e julho de 2003, sendo os dois primeiros mais significativos. De acordo com os resultados de variação de volume acumulado, a praia recebeu significativo estoque de sedimentos durante o monitoramento realizado, chegando a seu máximo deposicional no último mês de coleta de dados (Fig. 3). Ao final de 13 campanhas, o perfil 2 apresentou um ganho de $18,23 \mathrm{~m}^{3} / \mathrm{m}$ no estoque sedimentar subaéreo em relação ao primeiro perfil medido. A maior variação negativa de volume relativo ocorreu na segunda campanha, em setembro de 2002 $\left(-9,32 \mathrm{~m}^{3} / \mathrm{m}\right)$. A maior variação positiva ocorreu na terceira campanha, em outubro de $2002\left(+8,04 \mathrm{~m}^{3} / \mathrm{m}\right)$. O 
Perfil 1

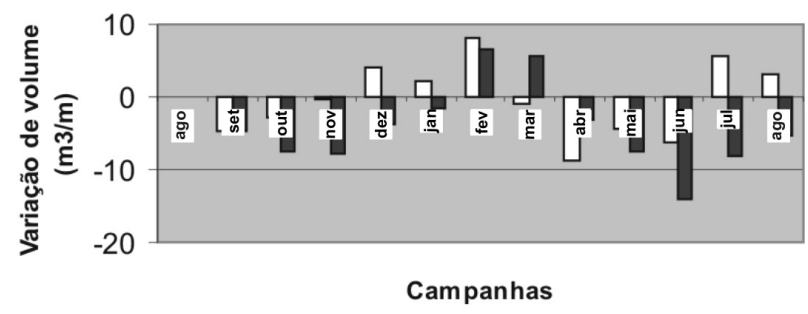

$\square \vee v$ relativo $\square \vee v$ acumulado

Perfil 2

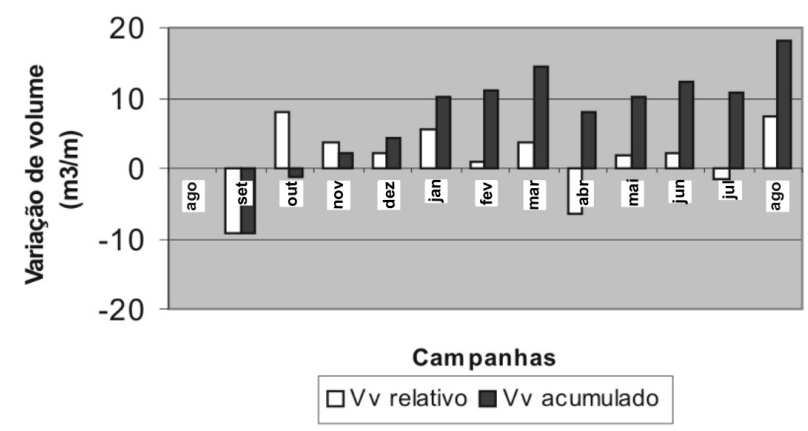

Perfil 3

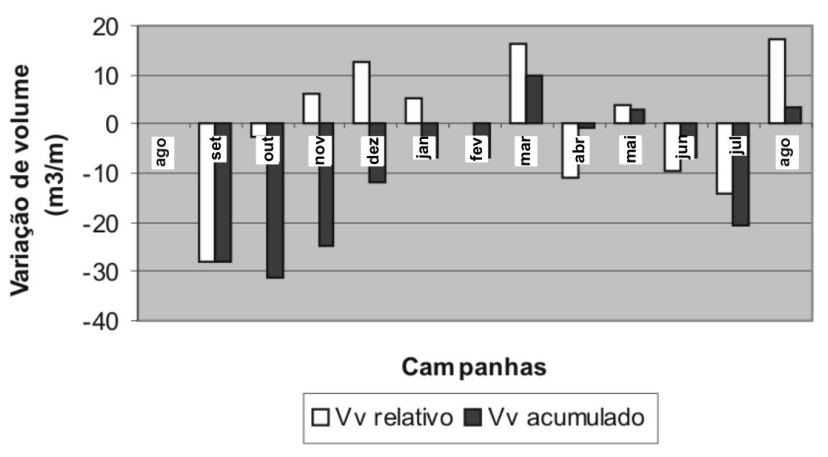

Figura 3 - Gráficos com variações de volume de sedimento, relativo a cada mês monitorado, e acumulado a partir do primeiro mês, referentes aos três perfis monitorados entre agosto de 2002 e 2003.

período onde o perfil apresentou menor volume de sedimentos acumulado ocorreu em setembro de 2002.

Durante o período amostral, o perfil 3 esteve sujeito às variações negativas e positivas de sedimento na parte subaérea (Fig. 3), e foi aquele onde houve as maiores variações morfológicas. Períodos de erosão ocorreram nos meses de setembro a outubro de 2002 e nos meses de abril, junho e junho de 2003. Já períodos de deposição ocorreram entre novembro de 2002 e março de 2003 e nos meses de maio e agosto de 2003, quando ocorreu o desenvolvimento da berma. Durante o mês de fevereiro, o perfil permaneceu estável. Quanto à variação de volume acumulado, observou-se que a praia perdeu sedimentos até outubro de 2002. A partir daí, recuperou gradualmente seu estoque sedimentar, chegando a seu máximo acrescivo em março de 2003. A maior taxa de deposição de sedimentos subaéreos do perfil 3 foi registrada entre fevereiro e março de 2003 $\left(+16,48 \mathrm{~m}^{3} / \mathrm{m}\right)$, enquanto que a maior taxa de erosão ocorreu entre agosto e setembro de $2002\left(-28,23 \mathrm{~m}^{3} / \mathrm{m}\right)$. Em abril, o perfil sofreu a primeira erosão após o verão, recuperando sedimentos em maio. Em junho e julho de 2003, a praia sofreu novo processo erosivo de sedimentos subaéreos, conseguindo recuperar sedimento em agosto. Ao final de 13 campanhas, o perfil 3 apresentou um ganho de $3,43 \mathrm{~m}^{3} / \mathrm{m}$ no estoque sedimentar subaéreo em relação ao primeiro perfil medido.

A variação média de volume encontrada foi de $3,95 \mathrm{~m}^{3} / \mathrm{m}$ no perfil 1 , de $4,06 \mathrm{~m}^{3} / \mathrm{m}$ no perfil 2 e de 9,79 $\mathrm{m}^{3} / \mathrm{m}$ no perfil 3 . A altura de onda média medida em campo no perfil 1 foi de $0,23 \mathrm{~m}$, no perfil 2 de $0,56 \mathrm{~m}$ e no perfil 3 de $0,77 \mathrm{~m}$. Levando em conta a variação de volume, ressalta-se que a variabilidade entre os perfis obedeceu à variação na energia de onda ao longo da praia.

Variabilidade dos perfis associada a períodos de alta energia de onda Para a área de estudo, a maior energia de onda ocorre devido às ondulações de sul-sudeste com período de pico de onda acima de $10 \mathrm{~s}$. Durante o período de monitoramento, dados de onda, obtidos pelo ondógrafo em águas profundas, indicaram que estes eventos de alta energia de onda ocorreram com maior freqüência no fim do inverno de 2002 e no outonoinverno de 2003. Os dados de variação de volume na praia indicaram que períodos erosivos ocorreram neste período, em setembro de 2002 e abril de 2003. A seguir, serão abordados os principais eventos relacionados aos períodos erosivos.

Duas fortes ondulações atingiram a área de estudo no início de setembro de 2002, uma no dia primeiro e outra no dia 7. Em ambos os casos, a altura significativa registrada no ondógrafo esteve acima de $4 \mathrm{~m}$ e o período acima de $10 \mathrm{~s}$ (Fig. 4a). A direção predominante era de sul-sudeste. Após estes eventos, foi medida erosão de $4,56 \mathrm{~m}^{3} / \mathrm{m}$ no perfil $1,9,32 \mathrm{~m}^{3} / \mathrm{m}$ no perfil 2 e 28,23 $\mathrm{m}^{3} / \mathrm{m}$ no perfil 3 (Fig. 3). Este alto valor para o perfil 3 corrobora a importância da variação de energia entre os setores para a variabilidade morfológica desta praia. $\mathrm{O}$ perfil 1 apresentou erosão na berma e duna frontal incipiente, aumento na largura da praia e pequeno aumento na declividade da face praial em relação ao mês de agosto. O perfil 2 apresentou deposição no pós-praia superior e erosão na berma, com diminuição na largura da praia em $10 \mathrm{~m}$ e aumento na declividade da face praial. O perfil 3 apresentou erosão no pós-praia e berma, diminuição na largura da praia e aumento na declividade da face praial, devido à erosão de parte da berma.

Nos dias 12 e 13 de abril, outra forte ondulação de sul-sudeste atingiu a costa catarinense (Fig. 4b), acarretando o desprendimento do ondógrafo localizado em águas profundas ao largo da área de estudo. Após este evento foi medida erosão de $8,79 \mathrm{~m}^{3} / \mathrm{m}$ no perfil $1,6,38$ $\mathrm{m}^{3} / \mathrm{m}$ no perfil 2 e $10,77 \mathrm{~m}^{3} / \mathrm{m}$ no perfil 3 , mais exposto (Fig. 3). O perfil 1 apresentou erosão na berma e dimi- 

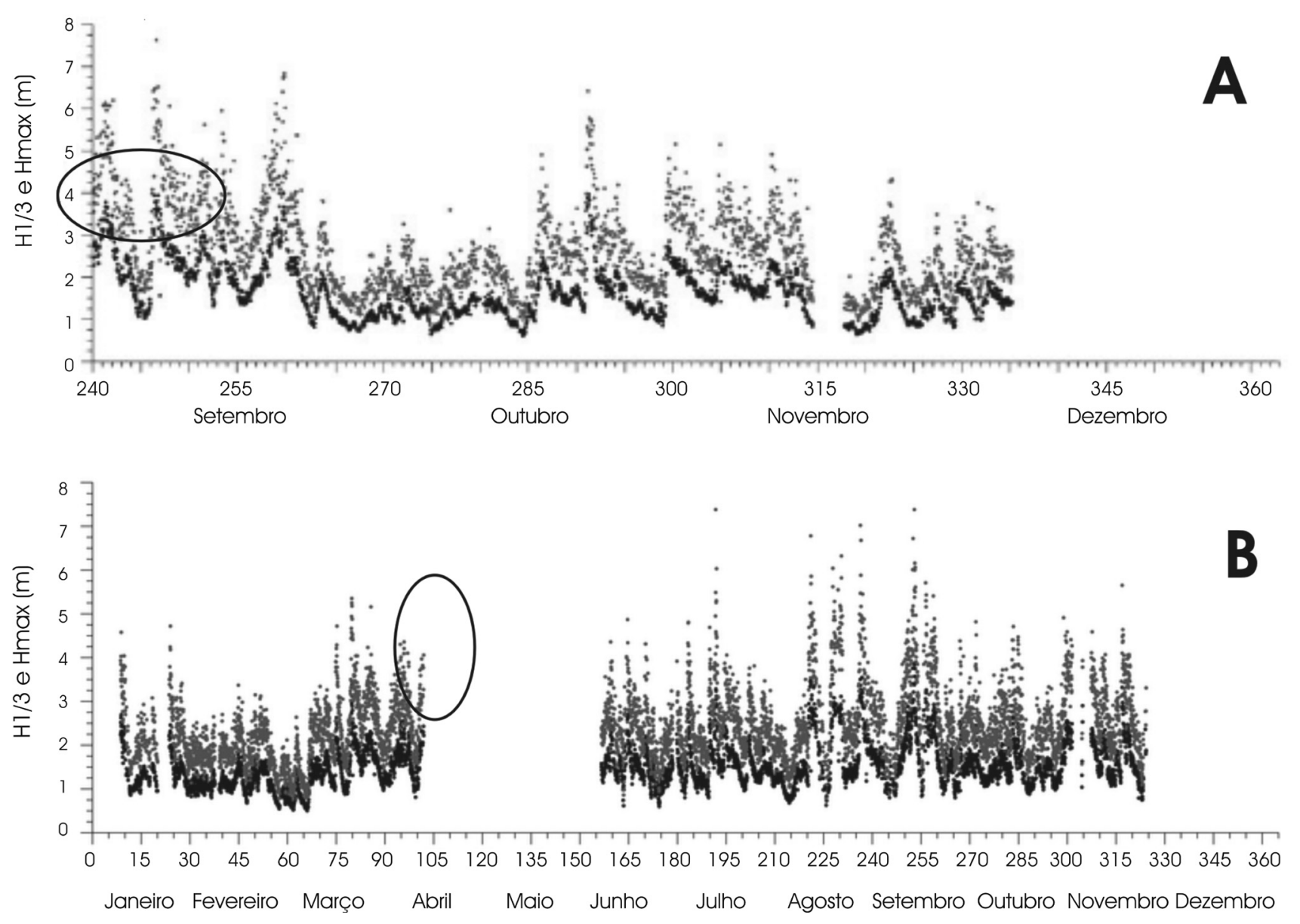

Figura 4 - Medidas de altura máxima (em cinza) e significativa (em preto) de onda, obtidas pelo ondógrafo entre setembro e dezembro de 2002 (A) e entre janeiro e dezembro de 2003 (B), mostrando em detalhe os períodos de maior energia de onda durante o periodo de monitoramento (Fonte: Modificado de Melo et al. 2003).

nuição na declividade da face praial em relação ao mês anterior, mantendo largura da praia estável. O perfil 2 teve erosão da berma, pequeno aumento na declividade e diminuição na largura da praia. O perfil 3 apresentou erosão em todo perfil, com diminuição na declividade da face praial e aumento na largura da praia.

Variabilidade dos perfis associada a períodos de baixa energia de onda Ondas de baixa energia na área de estudo decorrem da ação de vagas e ondulações com direção de incidência leste-nordeste, visto que a praia do Pântano do Sul é abrigada de ondas provenientes dessa direção (Fig. 1) e vagas, geralmente com período de pico de onda abaixo de $8 \mathrm{~s}$, provenientes de qualquer direção.

Entre outubro de 2002 e março de 2003, houve o predomínio de ondas de baixa energia (Figs. 3a, 3b), resultando em perfis de praia acrescidos, basicamente pelo desenvolvimento de uma crista de berma (Fig. 2). O perfil 1 teve o maior volume de sedimentos acumulados na porção subaérea da praia em fevereiro de $2003(6,46$ $\mathrm{m}^{3} / \mathrm{m}$ ) e o perfil 3 em março de $2003\left(9,81 \mathrm{~m}^{3} / \mathrm{m}\right.$ ) (Fig. 2). O perfil 3 também apresentou as maiores taxas de deposição, retratando sua maior variabilidade morfoló- gica. Já o perfil 2 teve seu maior volume acumulado em agosto de 2003, mas também apresentou perfis acrescivos entre janeiro e março de 2003 (Fig. 2). Períodos deposicionais ocorreram nos três perfis em dezembro de 2002 e em janeiro, fevereiro e agosto de 2003.

Quando ocorreu a diminuição do nível de energia das ondas, notou-se que a barra submersa migrou em direção a porção subaérea da praia. Observou-se também que a berma, quando desenvolvida, inibiu a ação do varrido no pós-praia superior e duna frontal, ocorrendo a expansão da vegetação dunar. A declividade da face praial geralmente aumenta nestes períodos devido ao deslocamento de sedimentos da zona de surf para a porção subaérea da praia (formação da berma).

Variabilidade dos perfis devido à presença de feições morfológicas caracterizadas como megacúspides praiais Após relacionar a variabilidade de perfis medidos à própria geomorfologia da costa e ao regime de ondas no período de monitoramento, buscou-se relacionar tais variabilidades às feições rítmicas de menor amplitude morfológica encontradas durante a medição dos perfis (cúspides e principalmente megacúspides praiais). 
Observou-se que a praia do Pântano do Sul exibiu forma plana à convexa dos perfis medidos junto à crista das megacúspides e morfologia côncava do perfil quando este foi medido junto aos embaiamentos das mesmas. Para exemplificar isto, na campanha de 13/06/2003 um perfil extra foi medido a $78 \mathrm{~m}$ a norte do perfil 2 , onde a característica descrita foi mais marcante.

Este exemplo mostra que o perfil 2, situado nesta data sobre a crista de uma megacúspide, apresentava $23 \mathrm{~m}^{3} / \mathrm{m}$ de sedimentos a mais de que o perfil $2 \mathrm{~b}$ (perfil extra), situado nesta mesma data sobre um embaiamento de megacúspide. Esta variabilidade também foi quantificada pelos parâmetros largura da praia e declividade. A largura da praia variou de $46,6 \mathrm{~m}$ no perfil 2 para 24,8 $\mathrm{m}$ no perfil $2 \mathrm{~b}$ enquanto que a declividade da face praial oscilou de $2^{\circ}$ no perfil 2 para $6^{\circ}$ no perfil $2 b$ (Fig. 5).

DISCUSSÃO Na ilha de Santa Catarina, assim como em boa parte do litoral sul-sudeste do Brasil, as praias arenosas possuem diferentes graus de curvatura de linha de costa em planta, sendo então expostas a diferentes direções de incidência de onda e sujeitas a distintos processos de circulação hidrodinâmica, transporte e deposição sedimentar.

Variações de comportamento praial ao longo da costa ocorrem devido à transformação sofrida pelas ondas à medida que estas se propagam em águas rasas, sendo influenciadas, entre outros fatores, pela declividade, largura, batimetria e tipo de fundo da plataforma continental e pela orientação da linha de costa (Calliari \& Klein 1993). Geralmente, quanto maior a exposição de um perfil praial ou trecho de costa em relação à direção de incidência predominante das ondulações, maiores são as variações morfológicas. Segundo Klein et al. (1997), isto ocorre porque numa praia protegida o regime de ondas junto à costa é mais uniforme que em praias expostas à energia de onda alta. Estas variações também podem ser influenciadas pela abundância de sedimentos existentes em cada praia.

Em geral, as variações morfológicas da praia do Pântano do Sul ocorreram em resposta à dinâmica costeira, forçada por processos hidráulicos introduzidos pelas ondas incidentes, correntes litorâneas e marés, sobre esta praia. Através do monitoramento realizado, foi possível identificar na praia do Pântano Sul um aumento da energia de onda a partir do setor nordeste (perfil 1), sujeito à baixa energia, para o setor sudoeste (perfis 2 e 3 ), sujeito a níveis de energia de onda moderados a altos.

Conforme mostrado em Oliveira (2004) e Oliveira et al. (no prelo), a praia do Pântano do Sul é uma praia que apresenta diferentes estágios morfodinâmicos "intermediários" segundo a classificação proposta por Wright \& Short (1984). Estes estágios variam ao longo da costa (espacialmente), visto que a praia apresenta um aumento da energia hidrodinâmica de um setor para outro. O setor nordeste (perfil 1) apresenta estágio morfodinâmico predominante "Terraço de Baixa Mar", com presença de mini-rips (canais de fluxo e refluxo de onda que ocorrem em praias de baixa-moderada energia de onda); o setor central (perfil 2) apresenta estágio bancos transversais e o setor sudoeste (perfil 3) estágios oscilando entre "Barras Transversais" e "Banco e Praia de Cúspide" (Fig. 6). Estes estágios morfodinâmicos referem-se principalmente a formas tridimensionais da zona de surf e face praial.

Geralmente, em um trecho de costa, estágios intermediários são mais variáveis, ao longo do tempo, comparado aos extremos dissipativo e reflectivo, pois estão sujeitos a períodos de alta e baixa energia de onda na costa. Porém, estes estágios intermediários apresentam diferenças de mobilidade de praia entre si, conforme mostrado amplamente na literatura. O estágio "Terraço de Baixa Mar", apontado pelo valor de ômega $(\Omega)$, parâmetro utilizado para classificar a praia quanto ao nível de energia (Wright et al. 1985), apresenta baixa energia de onda média e baixa variação de volume subaéreo se

\section{Perfis cúspide-em baiamento}

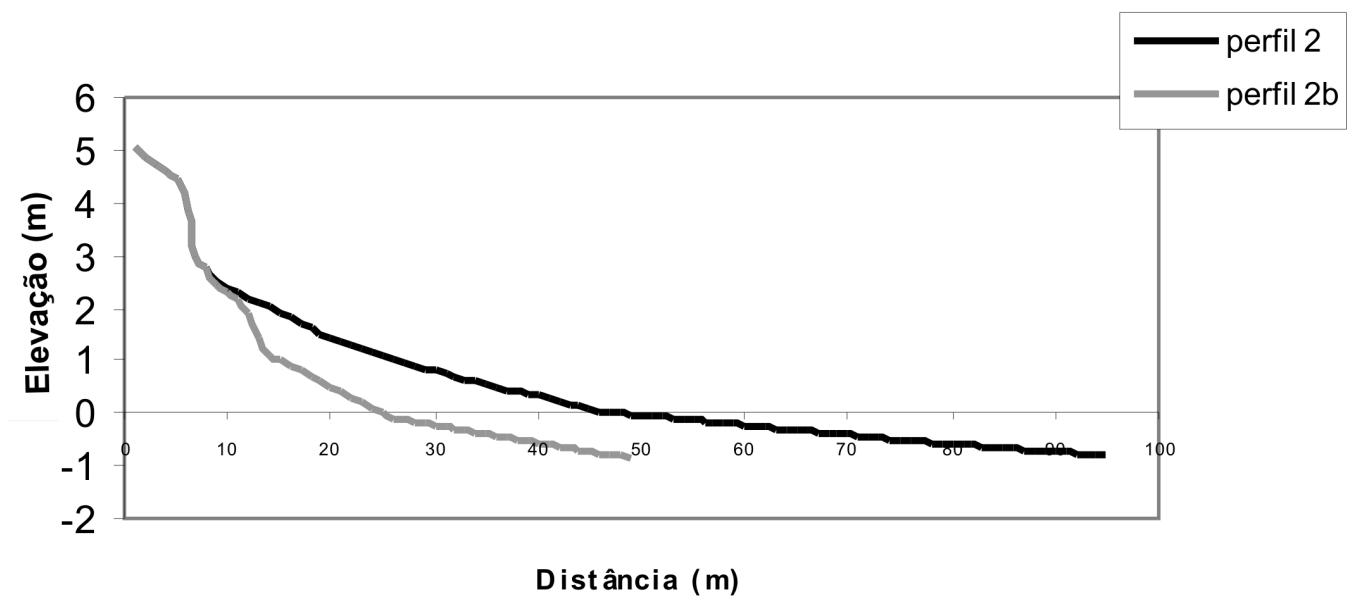

Figura 5 - Perfis 2 e 2b, obtidos no dia 13/06/2003, respectivamente sobre uma ponta e sobre um embaiamento de megacúspide. 

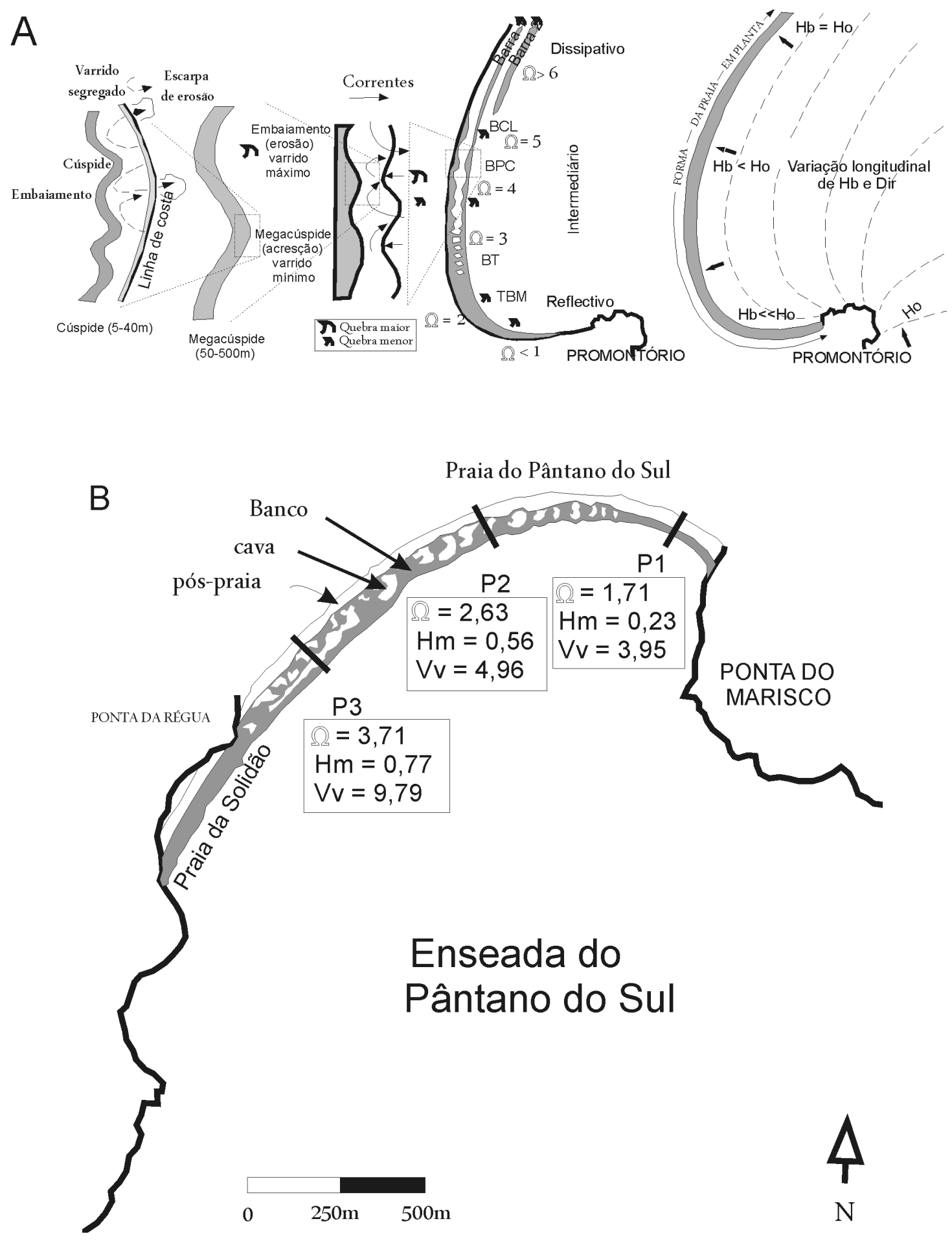

Figura 6 - Incidência de ondas e variação da morfologia ao longo de uma praia de enseada (Fonte: Modificado de Short 1999); (B) morfologia longitudinal instantânea do banco ao longo da praia do Pântano do Sul com valores do parâmetro adimensional ômega $(\Omega)$, altura média de onda $(\mathrm{Hm})$ e variação de volume subaéreo (VV) referentes aos três perfis de praia (Fonte: Modificado de Oliveira et al. no prelo).

comparado aos outros estágios intermediários encontrados na área de estudo (P2 e P3). Já os estágios "Bancos Transversais" e "Banco e Praia com Cúspides" que caracterizam os outros setores da praia, associados a au- mento na altura de onda, tiveram variabilidade morfológica ampliada progressivamente (Fig. 6).

Se, por um lado, ocorrem variações espaciais ao longo da linha de costa, variações observam-se tam- 
bém em cada trecho da costa ao longo do tempo. Geralmente, em períodos de alta energia de onda ocorre a retirada de sedimentos da porção subaérea da praia e o transporte deste material em direção ao mar, desenvolvendo muitas vezes formas aproximadamente lineares, com perfil mais plano, conforme descrito para outras praias por Lippmann et al. (1993). Quando há uma diminuição subseqüente do nível de energia hidrodinâmico, ocorre o movimento contrário. As barras tendem então a migrar em direção à porção subaérea da praia, muitas vezes desenvolvendo formas rítmicas, como as crescentes (Short \& Aagard 1993). Isto faz com que o estoque de sedimentos concentre-se cada vez mais próximo da face praial e da porção subaérea da praia, podendo, após longos períodos de baixa energia, formar praias reflectivas. Segundo Holman \& Sallenger (1993), processos deposicionais ocorrem lentamente se comparados aos períodos erosivos que se manifestam de forma mais brusca, causados geralmente por eventos de tempestade ou de alta energia de onda, localmente chamados de "ressacas".

No Pântano do Sul, a análise dos perfis de praia indicou que alguns perfis erosivos e acrescivos ocorreram sob mesmas condições: erosão após eventos de alta energia de onda, no caso ondulações de sul-sudeste associadas a sistemas de baixa pressão estabelecidos sobre o Atlântico Sul, e deposição durante o predomínio da baixa energia e/ou ondas provenientes do quadrante leste-nordeste. Isto ocorre também pelo fato da praia do Pântano do Sul possuir orientação predominante lesteoeste oscilando para nordeste-sudoeste, sendo exposta às ondulações de sul-sudeste e abrigada das vagas e ondulações de leste-nordeste.

Araujo et al. (2003), baseados na análise de dados do ondógrafo, sugeriram que durante o outonoinverno as ondulações prevalecem sobre as vagas e que na primavera as vagas prevalecem sobre as ondulações, identificando uma sazonalidade no clima de ondas.

Entre agosto de 2002 e 2003, eventos de alta energia de onda ocorreram com maior periodicidade no fim do inverno de 2002 e outono-inverno de 2003, enquanto que a baixa energia de onda predominou entre outubro de 2002 e março de 2003. Nos meses próximos ao verão, predominaram períodos acrescivos e no outono/inverno erosivos, associados a eventos de alta energia de onda. De uma maneira geral, a praia apresentou regime sazonal quanto às variações no estoque sedimentar subaéreo, com deposição durante o final da primavera e verão e erosão no outono inverno, como resposta às variações do regime de ondas durante este período, exceto em alguns momentos no perfil 2 . Observou-se que, entre agosto de 2002 e 2003, não foram todos os eventos de alta energia de onda que tiveram a capacidade de erodir a praia. Também se observou que esta praia apresentou boa capacidade de recuperação no estoque sedimentar subaéreo após processos erosivos.

Os processos de erosão e deposição encontrados nos perfis, além de estarem relacionados à diferença de energia espacialmente ao longo da praia (perfis 1, 2 e 3 ) e temporalmente em cada trecho da praia (de agosto de 2002 a agosto de 2003), como abordado em parágrafos anteriores, também se relacionam com a formação e migração de feições rítmicas encontradas na área de estudo, como mini-rips, cúspides praiais e principalmente megacúspides, responsáveis pelas maiores variações tridimensionais nesta praia. Em diversas campanhas amostrais, a praia do Pântano do Sul apresentou morfologia plana à convexa dos perfis situados junto às mini-rips (no perfil 1), cúspides praiais (que podem ocorrer em toda praia) e megacúspides (nos perfis $2 \mathrm{e}$ 3 ), pendendo a um estado côncavo dos perfis junto aos embaiamentos intercalados.

Segundo Inman \& Guza (1982), estas feições morfológicas são forçadas pela ação das chamadas ondas de borda (edge waves), geradas a partir do movimento de energia das ondas gravitacionais. A combinação entre ondas incidentes e a forma de praia antecedente produzem as ondas de borda que, por sua vez, constroem padrões rítmicos de sedimentação na praia subaérea (Komar 1976). Para Souza et al. (2005), a ritmicidade da praia é mais favorecida quando as ondas incidentes se aproximam "normal" à costa, isto é, quebram praticamente ao mesmo tempo, fato comumente observado na área de estudo, e que favoreceu períodos erosivos e deposicionais simultâneos em todos os trechos da praia estudados.

Como já abordado anteriormente, o setor nordeste (perfil 1) apresenta o estágio "Terraço de Baixa Mar" como predominante, com presença de mini-rips, o setor central (perfil 2) "Bancos Transversais" e o setor sudoeste (perfil 3) varia entre os estágios "Bancos Transversais" e "Banco e Praia de Cúspides". No perfil 1 , setor nordeste, a praia apresenta apenas pequenos canais de drenagem do varrido, as mini-rips, que causam pouca variação de volume entre os embaiamentos inter mini-rips e os trechos restantes do terraço de maré baixa. Já no perfil 3, setor sudoeste, a presença de correntes longitudinais e bermas (praia com banco e praia de cúspide) tornam muitas vezes o pós-praia pouco variável tridimensionalmente, sem a presença significativa de pontas e embaiamentos de megacúspides. Diferentemente destes, o perfil 2 , situado no setor central da praia, quase sempre apresentou alta ritmicidade morfológica, com alternância de barras transversais e correntes de retorno registradas na maioria das campanhas de amostragem. Estas feições, juntamente com a utilização do parâmetro adimensional ômega, fizeram com que este trecho de praia fosse classificado como intermediárias "Barras Transversais", de Wright \& Short (1984).

O estágio intermediário "Barras Transversais" representa a máxima segregação lateral de fluxo propiciando o desenvolvimento de correntes de retorno, principalmente quando as extremidades dos bancos se soldam à porção subaérea da praia (Calliari et al. 2003.), o que gera feições típicas como cúspides e megacúspides, formadas na face praial pelo espraiamento. Estas geralmente apresentam alta variabilidade morfológica espacial entre as cristas e os embaiamentos. Durante o monitoramento praial, foi medida significativa variação de volume entre a crista e o embaiamento de uma 
megacúspide para o mesmo período de amostragem no perfil 2. Esta característica rítmica presente na praia na forma de megacúspides praiais fez o perfil 2 destoar da relação encontrada entre a variação do estoque sedimentar e o regime de ondas da área descrita nas secções anteriores. Provavelmente o perfil 2 não apresentou a mesma variabilidade temporal dos outros dois (P1 e P3) (Fig. 3), pois, entre agosto e dezembro de 2002, quando predominou a deposição sedimentar na praia do Pântano do Sul, este perfil esteve situado sobre o embaiamento de uma megacúspide. Posteriormente, entre abril e agosto de 2003, quando a praia foi erodida, o perfil 2 situou-se sobre a crista de uma megacúspide. Isto não foi medido, mas registrado nas planilhas de campo.

CONCLUSÕES A variabilidade morfológica espaço-temporal da praia do Pântano do Sul, ocorre em decorrência dos seguintes fatores:

(i) Grau de exposição dos diferentes trechos da praia às ondas incidentes. Quando mais exposta à ação de ondas, a praia tendeu a apresentar maiores variações no estoque sedimentar, como ocorreu no perfil 3, visto que nestes locais a energia de onda varia mais. Se a ação das ondas pouco varia, como ocorreu no perfil 1 , a variação morfológica do perfil é pequena. A diferença na variação média de volume entre os três perfis ocorreu principalmente devido à gradação de energia de onda ao longo da praia.

(ii) Ação de ondas de alta energia na praia, caracterizada pela incidência de ondulações de sul-sudeste com período de pico de onda acima de $10 \mathrm{~s}$ e altura significativa acima de $4 \mathrm{~m}$ em águas profundas (geradas por sistemas de baixa pressão estabelecidos sobre o oceano Atlântico); observa-se erosão de toda a porção subaérea da praia durante e logo após esses eventos;

(iii) Ação de ondas de baixa energia na praia. Vagas e ondulações com direção predominante de lestenordeste, visto que esta praia é abrigada desta condição de mar pelo embasamento cristalino, assim como ondas de baixa energia em águas profundas, provenientes de qualquer direção, acarretam na deposição sedimentar da praia subaérea.

(iv) Morfologia rítmica da praia, que pode gerar variações espaciais locais na declividade e no volume entre perfis medidos sobre pontas e sobre embaiamentos das megacúspides, freqüentes nos setores central e sudoeste da praia. Esta morfologia rítmica é gerada pela combinação entre ondas incidentes e ondas de borda. Geralmente, a praia é mais larga e de menor declividade, junto às cristas, e mais estreita e com maior declividade, nos embaiamentos. Isto pode ser notado principalmente no perfil 2, onde o estágio morfodinâmico "Barras Transversais", com presença de megacúspides, criaram relação entre variação do estoque sedimentar e regime de ondas destoante da encontrada nos outros dois perfis.

Neste contexto, a praia do Pântano do Sul Açores pode ser considerada sujeita, espacial e temporalmente, a diferentes níveis de energia de onda e conseqüentemente a diferentes padrões de variabilidade morfológica. Analisando a diferença de morfologia entre os perfis e levando em consideração todos os aspectos de variabilidade explorados, foi possível diagnosticar que, nesta praia, a maior forçante da variabilidade morfológica está relacionada à exposição média de onda na praia, a variação espacial. Dentro de cada trecho de praia, a ação da alta e da baixa energia de onda ao longo do tempo acarreta erosão e deposição do estoque subaéreo da praia. Esta variação, no entanto, não é homogênea devido aos diferentes graus de exposição de cada trecho. O desenvolvimento e erosão da berma e das características rítmicas presentes na praia foram as principais variações morfológicas encontradas e medidas durante o período de monitoramento.

Agradecimentos Os autores agradecem a CAPES pela concessão de bolsa de pós-graduação em nível de mestrado. Ao Programa de Pós-graduação em Geografia da UFSC pelo apoio recebido. Aos colegas Daniel Ribeiro, Daniel Simó, Felipe Caron, Frederico Rudorff, Jasiel Neves e Renato Lelis por terem auxiliado nos trabalhos de campo e atividades de laboratório. Ao professor Eloi Melo Filho (Lahimar/UFSC) pela disponibilização dos dados do ondógrafo. Aos professores Lauro Júlio Calliari e Jarbas Bonetti pelas críticas e sugestões no desenvolvimento deste trabalho.

\section{Referências}

Araújo C.E.S., Franco D., Melo Filho E., Pimenta F. 2003. Wave regime characteristics of southern Brazilian coast. In: International Conference on Coastal and Port Engineering in Developing Countries, COPEDEC, 6, Colombo, Sri Lanka, Paper No.97, 15p, CDRom

Birkmeier W.A. 1981. Fast accurate two-person beach survey. Coastal Engineering Technical Aid 81-11. U.S. Army Engineers Waterways Experiment Station. Vickburg, Mississippi, Coastal Engineering Research Center, Vickburg, 22 p.

Birkmeier W.A. 1985. A users guide to ISRP: The Interactive Survey Reduction Program. Department of the Army. U.S. Army Corps of Engineers. Washington, DC, CERC
Instruction report, Washington, CERC, 84 p.

Calliari L.J. \& Klein A.H.F. 1993. Características morfodinâmicas e sedimentológicas das praias oceânicas entre Rio Grande e Chuí, RS. Pesquisas, 20(1):48-56.

DIRETORIA DE HIDROGRAFIA E NAVEGAÇÃO. 2002. Tábua de marés 2002: Porto de Florianópolis. Rio de Janeiro: Marinha do Brasil.

DIRETORIA DE HIDROGRAFIA E NAVEGAÇÃO. 2003. Tábua de marés 2003: Porto de Florianópolis. Rio de Janeiro: Marinha do Brasil.

Gré J.C.R., Abreu de Castilhos J., Horn Filho N.O. 1995. Quaternary deposits of the Pântano do Sul beach, Santa Catarina Island, Brazil. In: Argollo J. \& Mourguiart 
P. (eds.) Climas Cuaternários en America del Sur. La Paz, Bolivia: Proyecto PICG - 281 / ORSTOM, cap.7, p. 121-131.

Holman R.A. \& Sallenger Jr. A.H. 1993. Sand bar generation: a discussion of the Duck experiments series. Journal of Coastal Research, SI(15):76-92.

Inman D.L. \& Guza R.T. 1982. The origin of swash cusp on beaches. Marine Geology, 49:133-148.

Klein A.H.F., Temme B., Menezes J., Diehl F.L., Carvalho J.L.B., Jabor P.M. 1997. Comportamento morfológico de uma praia semiprotegida: Praia central de Balneário Camboriú, Santa Catarina. In: Simpósio da ABEQUA, 6, Curitiba, Atas, p. 82-84.

Komar P.D. (ed.) 1976. Beach processes and sedimentation. New Jersey, Englewood Cliffs, Prentice Hall, 429p.

Lippmann T.C., Holman R.A., Hathaway K.K. 1993. Episodic, nonstationary behavior of a double bar system at Duck, N.C., U.S.A., 1986-1991. Journal of Coastal Research, SI(15):49-75.

Mariotti M.T. \& Franco D. 2001. Análise ARIMA da resposta do nível do mar a forçantes atmosféricas locais. 2003. In: Seminário sobre ondas, marés e engenharia oceânica, 4, Arraial do Cabo (RJ.), Atas, p. 21-22.

Melo E. 2002. Projeto Sentinelas do Mar: Instruções para efetuar as observações. Relat. Int. LaHiMar UFSC, Santa Catarina, No 001 p. 1-12. Disponível: www.lahimar. ufsc.br..Acessado em 23 de abril de 2008

Melo E., Pimenta F.M., Mendes D.A.R., Hammes G.R., Araújo C.E.S., Franco D., Alves J.H.G.M., Barletta R.C., Souto A.M., Castelão G., Pereira N.C., Branco F.B. 2003. A Real Time, On-line Coastal Information Program in Brazil. In: International Conference On Coastal And Port Engineering In Developing Countries, COPEDEC, 6, Colombo, Sri Lanka, Paper No.104, 14p, CDRom.

Nimer E. 1989. Climatologia da região Sul. Revista Brasileira de Geografia, 34(1):142-154.

Oliveira U.R. 2004. Comportamento morfodinâmico e granulometria do arco praial Pântano do Sul-Açores, Ilha de Santa Catarina, SC, Brasil. Florianópolis. Disserta- ção de Mestrado em Geografia, Universidade Federal de Santa Catarina, 102p.

Oliveira U.R., Barletta R.C.B., Peixoto J.R.V., Horn Filho N.O. (no prelo). Características morfodinâmicas da Praia do Pântano do Sul, Ilha de Santa Catarina, Brasil. Pesquisas Características morfodinâmicas da Praia do Pântano do Sul. Revista Pesquisas em Geociências (aceito, sem data de publicação).

Short A. D. 1999. Beaches. In: Short A.D. (ed.) Handbook of beach and shoreface morphodynamics. Chichester, p. 1-20.

Short A.D. \& Aagard T. 1993. Single and multi-bar beach changes model. Journal of Coastal Research, 15:141157.

Souza C.R.G., Souza Filho P.W.M., Esteves L.S., Vital H., Dillenburg S.R., Patchineelam S.M., Addad J.E. 2005. Praias arenosas e erosão costeira. In: Souza C.R.G., Suguio K, Oliveira A.M.S., Oliveira P.E. (eds.) Quaternário do Brasil. Holos Editora, p. 130-152.

Sunamura T. 1988. Beach morphologies and their changes. In: Horikawa K. (ed.) Nearshore Dynamics and Coastal Processes. University of Tokyo Press, p. 133-166.

Trucollo E.C. 1998. Maré meteorológica e forçantes atmosféricas locais em São Francisco do Sul-SC. Dissertação de Mestrado, Engenharia Sanitária e Ambiental, Universidade Federal de Santa Catarina, 100p.

Wrigth L.D. \& Short A.D. 1984. Morphodynamics variability of surf zones in Australia. In: Komar P.D. (ed.) Handbook of coastal processes and erosion. Florida, CRC Press, Boca Raton, p. 35-64.

Wrigth L.D., Short A.D., Green M.O. 1985. Short terms changes in the morphodynamic states of beach and surf zones. Marine Geology, 62:339-364.

Manuscrito ID 9170

Submetido em 25 de setembro de 2007 Aceito em 20 de setembro de 2008 Sistema eletrônico de submissão 